\title{
A REPRESENTAÇÃO DE SI NA ESQUIZOFRENIA ATRAVÉS DO PSICODIAGNÓSTICO DE RORSCHACH ${ }^{1}$
}

\author{
Manoel Antônio dos Santos ${ }^{2}$
}

RESUMO: O presente trabalho tem por objetivo discutir a relação entre a representação de si e a organização psíquica na esquizofrenia, através do psicodiagnóstico de Rorschach. A pesquisa foi realizada com uma amostra de 20 pacientes ambulatoriais adultos do sexo masculino, diagnosticados como esquizofrênicos. Para uma avaliação sistemática das respostas obtidas, foi aplicado um instrumento de análise de conteúdo, de acordo com critérios e referenciais interpretativos propostos pela literatura. Os dados obtidos evidenciaram um severo comprometimento da estrutura representacional, bem como uma escassa projeção de dinamismo e de atividade interacional nos perceptos. $O$ mundo interno do esquizofrênico é precariamente ordenado e integrado, marcado por uma acentuada indiferenciação afetiva e por representações de si arcaicas e regressivas, resultando no empobrecimento da personalidade. As implicações teóricas desses achados serão consideradas na discussão dos resultados.

Palavras-chave: esquizofrenia, representação de si, psicodiagnóstico de Rorschach.

\section{THE SELF REPRESENTATION IN SCHIZOPHRENIA: EVALUATION BY MEANS OF THE RORSCHACH TEST}

\begin{abstract}
This article discuss the relationship between the self representation and the psychic organization in schizophrenia, using the Rorschach psychodiagnosis test. The study was conducted on a sample of twenty adult male outpatients diagnosed as schizophrenics. An instrument of content analysis was applied for a systematic evaluation of the responses obtained, based on the criteria and interpretative frameworks proposed in the literature. Data analysis indicated a severe impairment of the structure of self representations, as well as a scarce projection of dynamism and of interactional activity in the perceptions. The inner world of the schizophrenic is precariously ordered and integrated, marked by a marked lack of affective differentiation, and by archaic and regressive representations of the Ego, resulting in the impoverishment of the personality. Theoretical implications are taken into account when discussing results.
\end{abstract}

Key words: schizophrenia, self representation, Rorschach test.

Uma das tendências mais marcantes nos estudos dos transtornos psicóticos através da aplicação do psicodiagnóstico de Rorschach é abordar os fenômenos patológicos associados aos quadros psicóticos desde o ponto de vista da atividade representacional que a técnica permite explorar (Anzieu \& Chabert, 1987; Chabert, 1987; 1990; Guelli, Jacquemin \& Santos, 1996; Mayman, 1967; Rausch de Traubenberg, 1981, 1986; Sanglade, 1983; Santos,

\footnotetext{
' Artigo recebido para publicaçăo em 04/00; aceito em 06/01

${ }^{2}$ Endereço para correspondência: Manoel Antônio dos Santos, Departamento de Psicologia e Educação da Faculdade de Filosofia, Ciências e Letras de Ribeirão Preto - USP. Docente do Programa de Pós-graduação en Psicologia, coordenador do NEPP - Núcleo de Ensino e Pesquisa em Psicologia Clínica. Endereço para correspondência: Av. Bandeirantes, 3900 - 14040-901 - Ribeirāo Preto - SP. E-mail: masantos@ ffclrp.usp.br

Paidéia, FFCLRP-USP, Rib. Preto, ago/dez/2000.
}

1991, 1992, 1996a, 1996b, 1997; Santos \& Jacquemin, 1990a). A representação de si, ou autorepresentação, tal qual expressa no exame de Rorschach, tem sido investigada na literatura especializada sobretudo com relação ao seu fenômeno correlato: a representação de objeto (Santos, 1996a).

Tal desenvolvimento teórico resulta da aplicação sistemática da teoria psicanalítica das relações de objeto (Meissner, 1979) e da representação mental (Beres \& Joseph, 1970) ao campo do psicodiagnóstico. Um dos desdobramentos mais fecundos desses aportes teóricos foi a elaboração de um quadro conceitual que nos permite tomar as respostas ao Rorschach como indicadores do mundo representacional internalizado pelo sujeito, formecen- 
do pistas sobre a organização dinâmica da personalidade, que se revelaram valiosas do ponto de vista diagnóstico e prognóstico.

Portanto, o estudo da representação de si (ou da representação do corpo) e do objeto através do Rorschach inicia-se com a investigação do papel que as representações dos objetos internalizados desempenham na constituição e estabilidade do ego (Rausch de Traubenberg, 1983). Dentro dessa concepção teórica, a existência de imagens do outro (objetos) dentro do self é considerada uma pré-condição do desenvolvimento emocional e social (Mayman, 1967).

A representação de si (Rausch de Traubenberg, 1981) supõe a existência de um sujeito capaz de refletir sobre si mesmo. Essa noção de Eu é uma conquista basicamente experiencial. Através das experiências repetidas de troca com o ambiente, a criança gradualmente adquire a percepção de si mes$\mathrm{ma}$, isto é, se descobre como um ser singular. À medida que tal percepção evolui e se torna constante, a criança também se torna capaz de se representar e de se comunicar com o mundo através das representações de si que elabora e re-elabora continuamente, constituindo um self organizado (Santos, 1996b, 1997).

De acordo com Marin (1991-92), o self representa o que há de mais íntimo em cada um de nós. Corresponde ao núcleo concreto de nossa identidade, que assegura nosso sentimento de permanência ao longo do tempo e do espaço (o sentido de ser), de continuidade (ser o mesmo em diferentes momentos de nossa existência), de coesão (ser unificado) e de coerência (ter um sentido). Esses sentimentos básicos fundam nossa identidade, organizam e dão sentido às nossas experiências.

A constituição da imagem de si é solidária à construção da imagem do corpo (Sanglade, 1983). Através da organização de uma imagem corporal estável e coerente, a criança tem a possibilidade de perceber, no cruzamento entre as relações narcísicas e as relações objetais, que há um self para ela e um self para os outros. É o que Rausch de Traubenberg e cols. (1990) notam, quando dizem que a representação de si no Rorschach inclui tanto a imagem do corpo fantasmático, como as relações dinâmicas que decorrem da formação dessa imagem e que a estruturam. As respostas ao Rorschach se equilibram nesse fio, às vezes tênue e difícil de se sustentar, en- tre dois níveis de exigências distintas: da atividade fantasmática, por um lado, e daatividade perceptiva, por outro (Rausch de Traubenberg, 1983, 1986; Rausch de Traubenberg \& Boizou, 1977). Por isso, pode-se esperar que a interferência excessiva de um nível sobre o outro esteja sempre presente nas psicopatologias, independentemente da especificidade da problemática.

Nesse sentido, é importante observar a presença das respostas de movimento nos protocolos. Elas indicam a existência de um compromisso possível entre a consigna de satisfazer, simultaneamente, as condições "objetivas" da percepção da realidade externa e a necessidade "subjetiva" de representar os desejos do mundo interno (Chabert, 1990).

A representação de si evolui através de uma imagem relativamente frágil do corpo, com contornos mal definidos e pouco diferenciados, em que os conteúdos psíquicos sofrem uma espécie de "derramamento" através das falhas do envelope corporal, até aquelas representações corporais mais integradas e estáveis, enriquecidas pela atribuição de dinamismo. $\mathrm{O}$ aparecimento de cinestesias evidencia o estabelecimento de fronteiras corporais bem definidas, mas também flexíveis o bastante para permitirem a passagem do fluxo constante de energia psíquica necessária às trocas afetivas com o mundo. Essas representações mais evoluídas são mediadas por engramas vívidos e calorosos, que se reatualizam continuamente através de experiências emocionais vivenciadas com os objetos, possibilitando a transformação e o crescimento da personalidade.

\section{Formulação do problema}

Para Modell $(1963,1973)$, problemas vividos no nível das relações de objeto mais precoces podem levar a uma predisposição à esquizofrenia. Friedman, Gunderson \& Feinsilver (1973, conforme citados por Perse \& Massuyeau, 1984), propõem que se compreenda a patologia esquizofrênica como um problema de funcionamento do Eu, determinado pelas relações precoces entre a criança e as figuras parentais, não excluindo a influência de elementos biológicos e constitucionais. Essạ distorção das relações objetais primárias resulta em uma incapacidade de organizar representações internas do mundo exterior adequadas, e de mantê-las distintas do seu mundo interno. 
Diversos autores postulam que a insuficiência das representações internas do mundo externo real (ou seja, de imagens-lembranças) está intimamente ligada às condutas patognomônicas do esquizofrênico na exame de Rorschach (Perse \& Massuyeau, 1984). Seguindo essa linha de raciocínio, podemos indagar ainda se essa problemática não estaria enraizada em uma virtual deficiência experienciada em termos da elaboração da imagem corporal e do sistema de auto-representação.

Na tentativa de elucidar essa questão, o presente estudo propõe-se a avaliar a consistência da representação de si no campo da esquizofrenia, através das respostas fornecidas por uma amostra de sujeitos portadores de graves transtornos emocionais.

\section{Método}

\section{Participantes}

Foram avaliados os protocolos Rorschach fornecidos por vinte pacientes ambulatoriais adultos do sexo masculino, diagnosticados como esquizofrênicos, com idades variando entre 21 e 46 anos.

Com relação à faixa etária, os sujeitos se distribuem da seguinte maneira: 11 (55\%) situam-se na faixa dos 20-29 anos, seis (30\%) dos 30-39 anos e três $(15 \%)$ dos $40-49$ anos.

Com referência ao grau de instrução, embora o nível de escolaridade varie desde a escolaridade primária até alguns anos de escolaridade superior, observa-se uma tendência ao predomínio de baixo nível de escolaridade para a maior parte dos sujeitos. Obteve-se a seguinte distribuição de sujeitos quanto ao perfil educacional: $75 \%$ dos pacientes apresentam apenas o $1^{\circ}$ grau (a maior parte, incompleto), predominando aqueles que alcançaram o que antigamente se convencionava chamar de "nível secundário" de instrução (o que corresponde atualmente da $5^{\mathrm{a}}$ a $8^{\mathrm{a}}$ série do $1^{\circ} \mathrm{grau}$ ). Assim, $50 \%$ têm o secundário incompleto, $10 \%$ têm o secundário completo, $10 \%$ o primário incompleto e $5 \%$ o primário completo. Não obstante, nota-se ainda uma parcela de pacientes que alcançaram o $2^{\circ}$ grau ( $15 \%$, sendo $10 \%$ completo e $5 \%$, incompleto) e curso superior incompleto $(10 \%)$.

No que diz respeito à atividade profissional, os pacientes ocupavam-se predominantemente de atividades que exigem baixo nível de especialização $e$ qualificação profissional (atividades basicamente relacionadas a vendas e escritório) ou que requerem apenas habilidade ou semi-habilidade manual (ajudante de mecânico, operador de máquina, marceneiro) ou sem habilidades manuais (serviços braçais em geral, lavrador, estivador, guarda-noturno, pintor, contínuo).

Por outro lado, é importante salientar que apenas sete sujeitos (35\%) encontravam-se profissionalmente ativos por ocasião da avaliação. Ou seja, uma parte substancial da amostra (65\%) é constituída de indivíduos que não se inseriam entre a população economicamente ativa, por ocasião da avaliação, não tendo nenhum tipo de ocupação ou inserção no mercado formal de trabalho. Viviam do benefício social que recebiam e do apoio da familia.

Do ponto de vista do estado civil, uma parcela expressiva da amostra (70\%) é constituída de indivíduos solteiros. Os seis restantes apresentavam a seguinte situação familiar: três eram casados (15\%) e três separados $(15 \%)$.

\section{Procedimento}

\section{Seleção da amostra}

Os sujeitos foram selecionados a partir de uma amostra casual de pacientes atendidos no Ambulatório de Clínica Psiquiátrica do Hospital das Clínicas da Faculdade de Medicina de Ribeirão Preto USP, dentro de um serviço de acompanhamento de tratamento psicofarmacológico (Ambulatório de Seguimento Medicamentoso). Os pacientes preenchiam os critérios diagnósticos para transtorno esquizofrênico, segundo avaliação realizada pelos psiquiatras do serviço.

Os pacientes foram incluídos no estudo quando o registro hospitalar (prontuário) especificava um diagnóstico claro e indiscutível de psicose esquizofrênica - 295, segundo a Classificação Internacional das Doenças - $9^{a}$ edição (Organização Mundial da Saúde, 1978), que era o sistema classificatório empregado pelo serviço à época em que foi realizada a coleta dos dados.

Um outro critério de inclusão adotado foi a possibilidade de o prontuário conter descrições suficientes acerca de transtornos de pensamento ou que, além da perturbação característica do pensamento esquizofrênico, relatasse conduta regressiva excên- 
trica, que justificasse o diagnóstico. Finalmente, um outro critério de inclusão na amostra foi não haver evidências de nenhuma outra enfermidade concomitante com as manifestações psiquiátricas associadas ao quadro esquizofrênico.

Foram considerados como critérios de exclusão a presença de alguma evidência de doença cerebral clara e de drogadição, associadas ao quadro psicótico. Essas exigências visavam assegurar que a amostra realmente fosse composta somente de pacientes diagnosticados como esquizofrênicos. Pacientes com outras desordens psicóticas e com distúrbios orgânicos associados ao quadro clínico (antecedentes de epilepsia, por exemplo) foram automaticamente excluídos, dado o objetivo de se obter uma amostra o mais homogênea possível. Ainda por este motivo foram eliminados aqueles casos em que, por ventu$\mathrm{ra}$, ainda restasse alguma dificuldade de distinguir o quadro esquizofrênico de outros distúrbios mentais. Da mesma maneira, foram eliminados os casos de deficiência mental (suspeita ou comprovada) e de deterioro intelectual considerável em função do quadro psicopatológico.

\section{Coleta dos dados}

Os dados foram coletados em sessões individuais, realizadas em sala com condições apropriadas, na instituição hospitalar da qual provinham os pacientes. A aplicação, apuração/cotação e interpretação dos resultados obedeceram às normas preconizadas para a técnica, de acordo com as recomendações de Rausch de Traubenberg (1975), levando-se em consideração as características peculiares da amostra.

\section{Análise dos dados}

Cada protocolo foi avaliado segundo as fórmulas convencionais da técnica, que permitiram constituir, preliminarmente, o psicograma de cada um dos sujeitos. Utilizou-se, para tanto, a nomenclatura francesa de Rausch de Traubenberg (1975) e os padrões normativos estabelecidos para o meio brasileiro por Augras (1986).

A avaliação dos protocolos foi realizada, independentemente, por dois psicólogos com experiência compatível na aplicação e interpretação da técnica, que serviram de juízes na etapa de categorização preliminar das respostas. Esse procedimento mostrou- se bastante satisfatório em termos da precisão das classificações, tendo em vista o alto nível de concordância encontrado. Utilizou-se o critério do acordo entre os dois juízes. Quando havia discordância entre os julgamentos realizados, a resposta era submetida a um terceiro juiz, com experiência semelhante na aplicação da técnica, e mantinham-se as cotações de consenso.

O mesmo procedimento foi seguido para a classificação das respostas segundo os critérios para aferição da representação de si. Nessa etapa de análise dos dados aplicou-se sobre as respostas obtidas um procedimento sistemático de análise de conteúdo, baseado em um instrumento proposto por Arcostanzo e seus colaboradores (Arcostanzo, Beglia \& Lertora, 1989; Arcostanzo, Beglia, Giordano \& Lertora, 1990). Esse instrumento, traduzido para o português pelo autor do presente estudo (Santos, 1996a), define os critérios e os referenciais interpretativos empregados para a avaliação da qualidade das representações produzidas em cada prancha. Uma descrição pormenorizada dos critérios de avaliação pode ser obtida consultando-se o Anexo 1 .

Os critérios postulados para a avaliação levam em consideração uma avaliação da qualidade da representação de si obtida em cada prancha, que pode ser considerada: positiva, negativa ou intermediária. Para tanto, seguem-se os pressupostos teóricos definidos pela escola francesa de interpretação do Rorschach, a saber: a organização do percepto em torno de um eixo central como ponto de referência para a representação corporal, a delimitação da mancha como referência para as fronteiras do Eu e a bilateralidade como marco que evoca o processo de separação-individuação. Uma representação foi considerada como tendo uma conotação positiva quando $\mathrm{a}(\mathrm{s})$ resposta $(\mathrm{s})$ oferecida à prancha apresentava(m) essas características. É importante. acrescentar que tais características constituem apenas princípios gerais norteadores da avaliação dos conteúdos. Além desses princípios gerais, os juízes receberam o sistema classificatório referido, que descrevia, de forma detalhada, o modo particular como essas características deveriam estar presentes nas respostas dos sujeitos. Esse instrumento oferece uma definição pormenorizada do que se pode considerar como uma representação de si positiva, negativa e intermediária, com exemplos ilustrativos de cada uma 
dessas categorias (Anexo 1).

Segundo Arcostanzo \& cols. (1989), a avaliação se baseia na qualidade da representação de si, no sentido positivo $(+)$, negativo $(-)$ ou intermediário $(+/-)$, com base em critérios específicos e diferenciados para as pranchas de I a VII, e para as pranchas em tom pastel (VIII a X). Uma atenção especial é dispensada às pranchas pastéis, nas quais se pode examinar o nível de integração dos componentes da emotividade e da afetividade em relação ao $\mathrm{Eu}$, assim como à relação existente entre o Eu e o mundo exterior.

\section{Resultados e Discussão}

A sistematização dos dados compreendeu um agrupamento das respostas submetidas à análise de conteúdo, considerando-se a totalidade de sujeitos que compõem a amostra. Os dados serão tratados dentro de uma abordagem estatística descritiva - uma análise percentual simples dos conteúdos das respostas, seguida de sua interpretação, a partir do referencial psicanalítico adotado.

Desse modo, considerando-se as pranchas tanto em seu conjunto como individualmente, esse tipo de análise de conteúdo deixa de se restringir às avaliações individuais, tradicionalmente empregadas com base nos significados simbólicos associados a cada prancha, e passa a permitir uma caracterização do grupo estudado como um todo, com relação às conotações com que a representação de si é investida.

A Tabela 1 apresenta o número de conotações qualitativas positivas e negativas das representações de si (R.d.S.) obtidas a partir da avaliação das respostas fornecidas por sujeito nas pranchas compactas.

A Tabela 2 apresenta o número de conotações qualitativas positivas e negativas das representações de si (R.d.S.) obtidas a partir da avaliação das respostas fornecidas por sujeito nas pranchas bilaterais.

Tabela 1: Conotação qualitativa da representação de si, segundo a prevalência de representações positivas ou negativas e a razão encontrada entre ambas, para cada um dos 20 sujeitos investigados, em função das diferentes representações fornecidas por sujeito nas pranchas compactas.

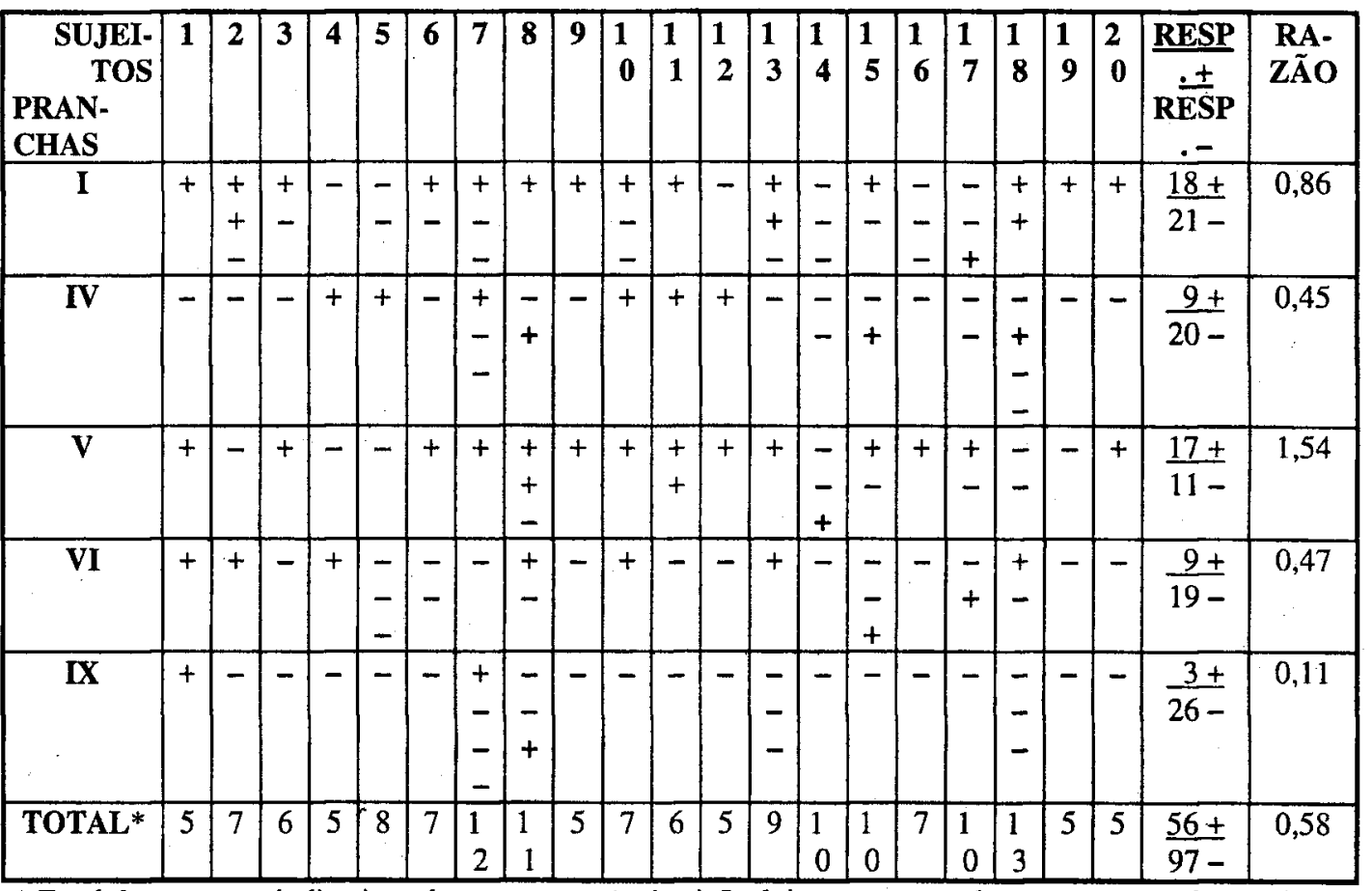

* Total de respostas indicativas de representação de si. Inclui as recusas e denegações, cotadas aqui como indicativas de representação de si negativa (-). 
Tabela 2: Conotação qualitativa da representação de si, segundo a prevalência de representações positivas ou negativas e a razão encontrada entre ambas, para cada um dos 20 sujeitos investigados, em função das diferentes representações fornecidas por sujeito nas pranchas bilaterais.

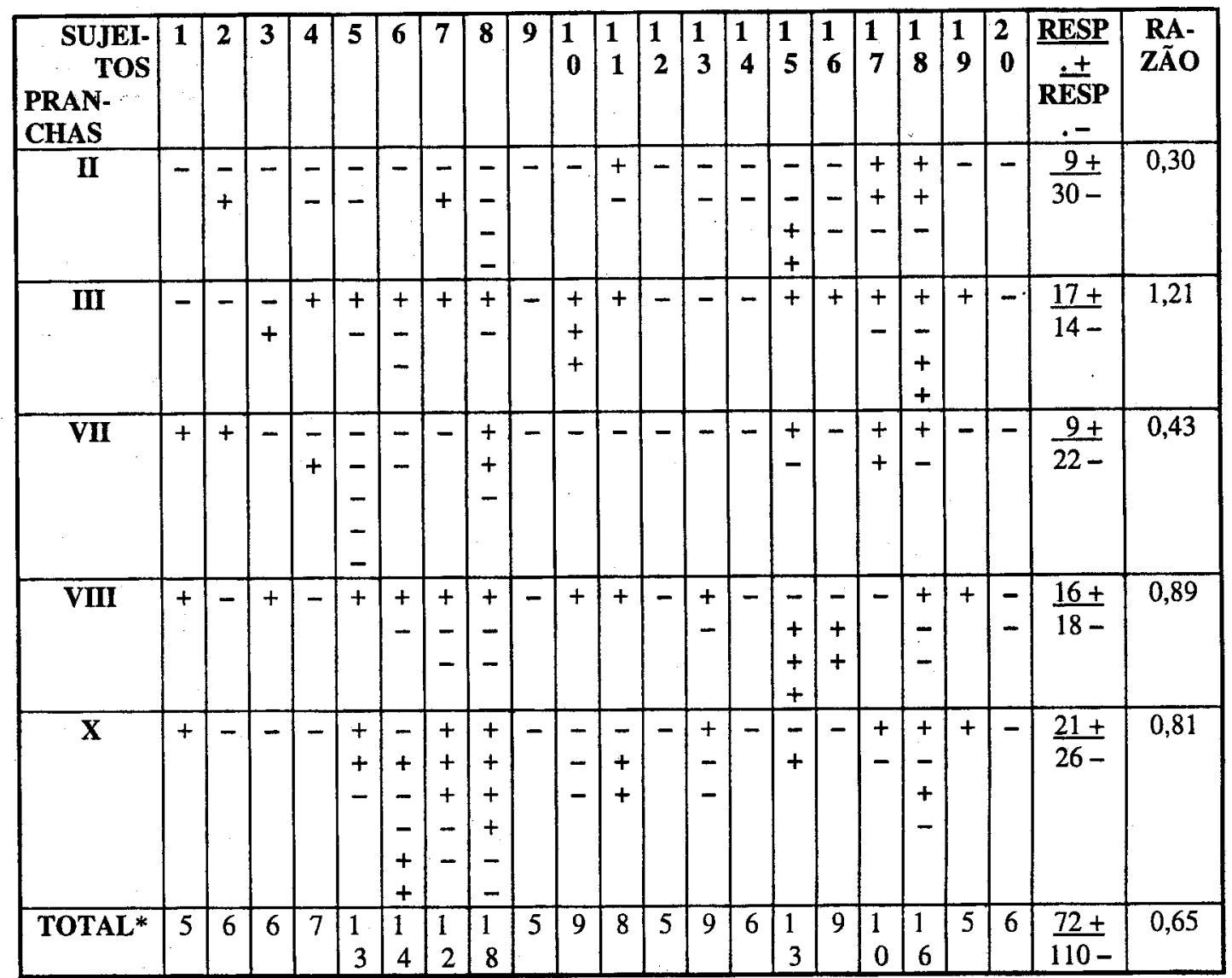

* Total de respostas indicativas de representação de si. Inclui as recusas e denegações, cotadas aqui como indicativas de representação de si negativa (-).

Considerando-se as pranchas individualmente, as Tabelas 1 e 2 apresentam uma visão panorâmica das qualificações positivas e negativas $(+$ ou - ) que foram atribuídas às respostas que compõem $o$ conjunto de 20 protocolos, de modo que se evidencia a proporção entre respostas contendo R.d.S. positiva e respostas contendo R.d.S. negativa (RESP.+/ RESP.-), quando se analisam as respostas isoladamente (e não o conjunto de respostas dadas a cada prancha, como será mostrado na tabela seguinte). O nível formal das representações foi avaliado levando-se em conta o modo como as respostas foram estruturadas em termos de diferenciação, articulação e integração dos diversos elementos componentes da resposta.

Comparando-se as produções nas pranchas bilaterais e compactas, observa-se que as pranchas bilaterais (II, III, VII, VIII e X) induziram um maior número de representações de si, em termos absolutos. Foram computadas 182 respostas indicativas de R.d.S., contrastando com 152 nas pranchas compactas (I, IV, V, VI e IX). Analisando-se a elaboração qualitativa das R.d.S. produzidas, observa-se que, na pranchas bilaterais, das 182 R.d.S. fornecidas, 110 tiveram conotação negativa contra 72 com conotação positiva. Nas pranchas compactas, 97 tiveram conotação negativa contra 56 com conotação positiva. Em termos proporcionais, a razão entre R.d.S. positivas e negativas foi semelhante quando se considera a totalidade das pranchas bilaterais e compactas $(0,65$ e 0,58 , respectivamente). Portanto, não se notou diferença substancial na conotação qualitativa das R.d.S. para o conjunto de pranchas bilaterais e

Paidéia, FFCLRP-USP, Rib. Preto, ago/dez/2000. 
compactas, o que sugere que não é possível diferenciar o desempenho do grupo de pacientes investigado com base na organização espacial das pranchas, quando se aplicam os critérios para avaliação da representação de si. Com base nesses dados, não foi possível corroborar a hipótese de que a organização compacta do estímulo pode favorecer o trabalho associativo do portador de esquizofrenia.

Analisando-se o conjunto dos dados sistematizados nas Tabelas 1 e 2, observa-se um claro predomínio de "respostas" negativas (-) sobre as "respostas" positivas $(+)$ em oito das dez pranchas do psicodiagnóstico de Rorschach. Assim, ocorre a prevalência de representações negativas nas pranchas (por ordem de importância): IX (compacta), II (bilateral), VII (bilateral), IV (compacta), VI (compacta) e, em menor proporção, nas pranchas X (bilateral), I (compacta) e VIII (bilateral).

Já nas pranchas V (compacta) e III (bilateral) as representações positivas são predominantes, o que evidencia que essas lâminas permitem melhor representação de si nos sujeitos estudados, ainda que a quantidade de representações negativas fornecidas nas mesmas possa ser considerada bem superior ao desejável (para cada representação negativa fornecida nessas pranchas, os sujeitos oferecem entre 1,2 e 1,5 representações positivas).

Passemos, agora, a uma análise mais pormenorizada do grau de elaboração das representações de si obtidas em cada prancha. Paralelamente, utilizaremos como referencial de análise temática os estudos de Anzieu \& Chabert (1987) quanto ao simbolismo específico de cada lâmina.

A prancha IX (compacta) caracteriza-se por um domínio excepcional das conotações negativas (26 em 29 respostas), o que traduz uma acentuada dificuldade de se auto-representar perante um estímulo que exige a assimilação das cores à forma, e que evoca, no nível simbólico, o modo como é vivenciado o relacionamento interpessoal profundo. Essa lâmina expressa, segundo Anzieu \& Chabert (1987), as relações afetivas mais íntimas e maduras, o que sugere que os pacientes esquizofrênicos apresentam elevado nível de comprometimento no estabelecimento de relacionamentos interpessoais. A propósito, lembremos o que diz Chabert (1987) a respeito das pranchas compactas como a IX. As lâminas com uma organização espacial compacta reque- rem, para que sejam reconhecidas como referências a um todo unificado e coerente, um sentimento de identidade estável.

Os sujeitos também apresentam na prancha II (bilateral) uma alta proporção de respostas que comportam uma representação de si de nível inferior ( 30 em um total de 39 respostas), o que dá a dimensão das dificuldades encontradas também no âmbito das pranchas bilaterais, denotando, nesse caso, dificuldades vivenciadas frente à simbólica materna implícita ao estímulo. A prancha II é aquela em que se evidencia um tipo de relacionamento mais profundo com a figura materna, com a qual o sujeito estabelece intercâmbio afetivo.

Segundo Chabert (1987), o tipo de relacionamento que começou a se esboçar na prancha I, com seu caráter mais primário, tenderia a ser continuado na prancha II. O vermelho evoca a sensibilidade do sujeito, favorecendo a expressão das trocas afetivas. Quando se constata na prancha I uma problemática ligada à figura materna, e na II o sujeito elabora boas respostas, pode-se postular que as situações de vida posteriores àquelas mais traumáticas e frustradoras favoreceram uma superação das experiências mais precoces. Contudo, quando as respostas continuam de má qualidade, como é o caso da amostra investigada, admite-se que as dificuldades prosseguem na vida adulta.

As respostas obtidas no presente estudo indicam que os pacientes demonstram uma ressonância ao simbolismo sexual da prancha II, onde as associações anatômicas remetem, antes de mais nada, à extrema permeabilidade dos envelopes corporais. Esses conteúdos assinalam a importância dos efeitos de transparência, como se a pele não se constituísse em uma membrana suficientemente espessa, o que testemunha a fragilidade do continente primário constituído (o Eu-pele, segundo Anzieu, 1985/1989). Tais respostas remetem, portanto, à reatividade imediata às excitações (presença do vermelho) e à confrontação relacional (configuração bilateral) pelo recolhimento narcísico (retorno do investimento libidinal ao próprio corpo) e pela fragmentação. Os movimentos pulsionais são, portanto, corroídos e petrificados por um contrainvestimento que explora a percepção em detrimento da descarga (predomínio de respostas $\mathrm{F}$ em vez de $\mathrm{K}$ ), e que enfatiza o interior do corpo em detrimento da relação de alteridade (anatomias, par- 
tes do corpo, em vez do esboço de um enredo que implique a relação entre dois parceiros representados de forma integrada e distintos entre si).

Considerando-se ainda a prancha II, observa-se que a sensibilidade especial ao vazio (o Dbl central) é indício de angústia devido a vivências de abandono e à falta de laços afetivos no relacionamento com o objeto primário. Em suma, pode-se notar que a dificuldade de identificação com a figura materna cria obstáculos à construção sólida tanto de uma identidade pessoal, como sexual. Por outro lado, esse estímulo permite elucidar um modo de relação dentro de um contex to bastante agressivo, como reação vivenciada diante do risco de esmagamento do Eu.

As pranchas IV, VI e VII situam-se em um patamar bastante semelhante em termos de predomínio das representações negativas sobre as representações positivas (em uma proporção em torno de 2,3 para 1). Do ponto de vista da organização espacial, vale lembrar que as pranchas IV e VI são compactas, enquanto que a prancha VII é bilateral. A prancha IV evoca, simbolicamente, a representação do modo como é percebida a relação com a figura paterna (ou, mais amplamente, a figura de autoridade, isto é, a relação interpessoal de domínio-submissão e a relação com o superego). Os resultados sugerem dificuldades marcantes na forma como foi introjetada a relação com a figura paterna, que constitui o suporte para a identificação sexual nos sujeitos masculinos.

A prancha VI é considerada a "prancha da sexualidade", enquanto que a VII solicita, novamente, a simbólica materna e a relação com o princípio da feminilidade. Ou seja, a prancha VII favorece o reconhecimento das relações precoces com a mãe, podendo representar, simbolicamente, a perda do contato com o objeto materno, onde o choque ao vazio (o espaço branco central percebido como "nada", algo que falta) evoca reações de vertigem (o risco de cair, de despencar no vazio), que podemos relacionar às falhas no estabelecimento do holding (Winnicott, 1952/1978).

Assim, observa-se nos protocolos estudados que tanto a prancha VI, como a VII, evocam a problemática sexual, em que o indivíduo parece estar retido diante da seguinte indagação: o que significa seu próprio sexo, e o que significa o sexo do outro? A prancha VI é considerada a prancha masculina, enquanto a VII, a feminina. Conseqüentemente, espera-se que o sujeito masculino se comporte de acordo com o padrão esperado diante de sua virilidade (prancha VI) e frente à feminilidade (prancha VII). $O$ tipo de representação majoritariamente elaborada pelo grupo esquizofrênico, e o fato de que as pranchas VI e VII evocaram o maior número de recusas, sugerem que a sexuálidade masculina não se encontra integrada à personalidade.

Já nas pranchas V (compacta) e III (bilateral) encontram-se os resultados mais favoráveis - ainda que aquém do esperado - obtidos pela amostra. A prancha $V$ é a prancha da representação de si mesmo e, portanto, da projeção do Eu. Uma outra hipótese clínica relacionada a essa prancha é a de que ela evoca o nível de adaptação à realidade exterior, bem como a adaptação àquilo que o indivíduo imagina que é.

Já a prancha III é indicativa da dinâmica dos processos identificatórios, constitutivos da matriz de identidade. Essa lâmina é freqüentemente relacionada à percepção do casal parental, e de um modo mais geral, à forma como as relações sociais, a identidade sexual e os papéis sexuais são vivenciados. Podemos supor que existe uma relação bastante estreita entre esses simbolismos e aquele suscitado pela prancha V. Esta, como vimos, proporciona a representação que o sujeito elabora acerca de si mesmo, bem como o seu sentimento de integridade corporal, enquanto que a prancha III possibilita vislumbrar como esse Eu é projetado nas relações interpessoais.

Em termos gerais, notamos assim que a problemática dos sujeitos, no plano da auto-representação, reside tanto a nível de pranchas compactas como bilaterais. Ou seja, os sujeitos, em seu conjunto, demonstram deficiências nos dois pólos de representações solicitadas pelo material da técnica. Segundo Chabert (1987), estes pólos correspondem à representação de si (pranchas compactas) e às representações de relações (pranchas bilaterais). Pode-se postular, portanto, que a articulação entre as duas dimensões que essas representações evocam narcisismo e relação objetal - encontra-se severamente comprometida nos pacientes esquizofrênicos.

As pranchas bilaterais, como a II, III, VII e VIII, evocam as representaçōes de relações, com sua dimensão especular que pontua as fontes narcísicas da personalidade. Desse modo, podemos inferir que o fracasso da auto-representação nas pranchas II, VII 
e VIII, evidenciado pela alta proporção de respostas que comportam uma representação de si de nível inferior, pode estar associado ao desenvolvimento de um narcisismo patológico, calcado em uma relação especular problemática estabelecida com o objeto primário (matriz simbólica das pranchas II e VII). A organização espacial das pranchas, que assume a forma de estímulos simétricos em relação a um eixo mediano, ao apelar para as "referências corporais" que fundam a projeção, encontra uma imagem do corpo mal-estruturada, que não faculta uma diferenciação satisfatória entre o mundo interno e o mundo externo, induzindo a dissolução dos limites, fator responsável pelos estados de interpenetração e confusão comumente observados nos protocolos de psicóticos (Chabert, 1987, 1990; Dreyfus, Husain \& Rouselle-Gay-Crosier, 1989; Dreyfus, Gay-Crosier \& Husain, 1983; Santos, 1991, 1992; Santos \& Jacquemin, 1990a, 1990b; Schafer, 1960; Silverman, 1970; Silverman \& Candell, 1963; Timsit \& Gross, 1989).

Nesse caos estrutural, que remonta às relações mais primitivas do ponto de vista do desenvolvimento psíquico, não ocorre discriminação suficiente entre o sujeito e o objeto. $O$ objeto é assimilado ao ego, isto é, englobado em termos de uma incorporação maciça que, inclusive, anula a possibilidade de representação de qualquer vestígio de diferenciação que por ventura possa emergir no seio dessa relação de intimidade psíquica. No contexto das interações que se estabelecem, podem ser freqüentes as "relações de inclusão sincrética" (Anzieu \& Chabert, 1987), os mútuos englobamentos, a interpenetração das identidades e as violentas intrusões recíprocas (Chabert, 1987). Pode-se supor, portanto, que a relação objetal adquire um caráter fundamentalmente sincrético, à medida que o objeto não é percebido senão como uma extensão ou prolongamento do próprio $\mathrm{Eu}$, e como tal é constituído do mesmo tecido que origina $\mathrm{o} E$, isto é, feito à imagem e semelhança do sujeito.

Como essa "imagem" que o sujeito elabora de si mesmo é deficiente, o objeto e a relação de objeto são investidos da mesma inconsistência que marca a representação de si. Assim, o laço especular que une o sujeito ao objeto não pode ser mantido, o que seria imprescindível para o fortalecimento das fronteiras egóicas, dentro de uma operação psíquica que conduz à fundação de um Eu narcísico. Observa-se, assim, o colapso do narcisismo primário.

Como se sabe, a representação de si é elaborada concomitantemente com o estabelecimento e o desenvolvimento das relações objetais, de cuja qualidade depende, por feedback, a consolidação de um narcisismo normal ou patológico. Quando o sentimento de identidade estável é deficiente, uma vez que a inconsistência das fronteiras egóicas não permite ao sujeito reconhecer-se como um todo unificado, a estruturação das fundações narcísicas do indivíduo torna-se comprometida pela representação de relações de objeto negativas, uma vez que as relações reais são vivenciadas como ameaça à frágil organização egóica.

Essas representações de relações objetais negativas, por sua vez, acabam contribuindo para cristalizar uma auto-representação negativa e depreciativa, conferindo-lhe um suporte identificatório defeituoso que ratifica, por reintrojeção, as falhas da auto-representação. Estabelece-se, assim, um círculo retroalimentador que, daí por diante, marcará continuamente todo o processo de projeção-introjeção, base do funcionamento psíquico segundo a teoria psicanalítica (Santos, 1999).

Os resultados relativos à conotação qualitativa da representação de si, preponderante nos 20 protocolos, considerados em sua totalidade, podem ser observados na Tabela 2.

Tabela 3: Qualidade da representação de si, segundo a prevalência de conotações positiva $(+)$, negativa $(-)$ ou intermediária $(=)$, observando-se o conjunto de 20 protocolos, considerados individualmente.

\begin{tabular}{|l|c|c|}
\cline { 2 - 3 } \multicolumn{1}{c|}{} & Sujeitos & $\%$ \\
\hline $\begin{array}{l}\text { Conotação } \\
\text { positiva (+) }\end{array}$ & 3 & 15,0 \\
\hline $\begin{array}{l}\text { Conotação } \\
\text { igual (=)* }\end{array}$ & 5 & 25,0 \\
\hline $\begin{array}{l}\text { Conotação } \\
\text { negativa (-) }\end{array}$ & 12 & 60,0 \\
\hline
\end{tabular}

* Conotação (=) designa equilíbrio entre a proporção de conotações $+\mathrm{e}-$ obtidas em um mesmo protocolo. 
De acordo com os dados obtidos, sistematizados na Tabela 3, pode-se observar que, na maioria dos protocolos (17, ou seja, $85,0 \%)$, a conotação predominante é negativa (-) ou intermediária (=), o que corrobora os resultados elaborados anteriormente, sublinhando o empobrecimento das auto-representações e/ou a marcada oscilação na qualidade das mesmas, que se mantêm quando se analisam os protocolos em sua totalidade. Apenas três protocolos $(15,0 \%$ da amostra) apresentam um predomínio de conotações positivas, o que pode estar associado a uma representação de si mais favorável e integrada.

\section{Conclusões}

Os dados obtidos sugerem um severo comprometimento da estrutura representacional associada com a organização egóica dos sujeitos. O mundo interno dos portadores de transtorno esquizofrênico mostrou-se precariamente ordenado e integrado, com acentuada indiferenciação entre o Eu e o objeto, o que leva a uma cisão severa das funções psíquicas (percepção, cognição e afetividade). Os engramas se organizam em torno de uma representação de si instável e pouco coerente, patente em uma profusão de imagens regressivas, desintegradas ou desvitalizadas, que provavelmente constituem o substrato psíquico para a fragmentação perceptiva e para a distorção da relação com o mundo.

Embora as pranchas com configuração bilateral suscitem mais fortemente a capacidade de síntese e as habilidades de coesão, concluímos que a problemática dos sujeitos no plano da auto-representação se inscreve tanto nas pranchas compactas como nas bilaterais. De fato, encontrou-se um amplo predomínio de representações com conotação negativa (prevalentes em oito pranchas), independentemente da configuração espacial dos perceptos.

As dificuldades de elaboração das pranchas menos estruturadas sugerem a fragilidade da adaptação fora dos domínios conhecidos e das soluções aprendidas. Já as pranchas V e III, nessa ordem, foram as que mais favoreceram uma melhor representação de si.

Em suma, a acentuação do processo psicótico pode ser apreendida através de uma representação corporal fragmentada, marcada pela transparência do envelope corporal, assim como dos modelos de relação arcaica que são privilegiados como recurso de- fensivo contra a ameaça constante de aniquilamento do Eu.

Esses indícios correspondem a uma identidade mal diferenciada, infiltrada pela confusão dos limites entre sujeito e objeto, que se defronta com a perda tanto do sentimento de permanência do objeto, como do sentido de continuidade e coesão do self, o que impede o acesso a uma representação de si integrada e a relações objetais mais maduras.

A escassa projeção de dinamismo e de atividade interacional nos perceptos denota o recurso à restrição maciça da expressão das necessidades emocionais como forma de auto-contenção dos impulsos. Trata-se de um mecanismo de defesa básico contra a marcada imaturidade afetiva. Com isso, fracassam os esforços para o estabelecimento de um padrão de relações interpessoais mais genuínas, que exigem trocas afetivas com o meio, resultando no empobrecimento da personalidade. A dissociação, vivida ao nível do Eu, do objeto e da percepção, pode assim repercutir também no aprofundamento das dificuldades de adaptação social, que intensificam a dissensão do grupo investigado em relação ao pensamento coletivo.

\section{Referências Bibliográficas}

Anzieu, D. (1989) O Eu-pele. (Z. Y. Rizkallah \& R. Mahfuz, Trad.) São Paulo: Casa do Psicólogo.

Anzieu, D. \& Chabert, C. (1987). Les méthodes projectives, $8 .^{a}$ ed. Paris: PUF.

Arcostanzo, G.; Beglia, G. \& Lertora, V. (1989). Rappresentazione di sé e relazioni oggettuali al Rorschach. Em Atti Giornata di Studio: "I test proiettivi tra indagine clinica e ricerca psicometrica" (pp.151-163).Genova: Università degli Studi di Padova.

Arcostanzo, G.; Beglia, G.; Giordano, D. \& Lertora, V. (1990). Validation de critères d'evaluation de la représentation de soi et des relations objectales au Rorschach. XIIIème Congrès Internationale du Rorschach et des Méthodes Projectives - Volume des Resumes. Paris: Centre de Psychologie Appliquée - SIRMP.

Augras, M. (1986) Teste de Rorschach-Atlas e dicionário: Padrões preliminares para o meio brasileiro. 6. ${ }^{\mathrm{a}}$ ed. Rio de Janeiro: Fundação Getúlic Vargas.'

Paidéia, FFCLRP-USP, Rib. Preto, ago/dez/2000. 
Beres, D. \& Joseph, E. (1970). The concept of mental representation in psychoanalysis. International Journal of Psycho-Analysis, 51, 9-11.

Chabert, C. (1987). La psychopathologie à l'épreuve du Rorschach. Paris: Dunod.

Chabert, C. (1990). Les potentialités de changement chez les adolescents psychotiques: Contribution du Rorschach et du TAT à une étude longitudinale. Revue de Psychologie Appliquée, 40(2), 113-137.

Dreyfus, A.; Gay-Crosier, I. \& Husain, O. (1983). Esquizofrenia simples e esquizofrenia paranóide através do Rorschach: Estudo comparativo. Análise Psicológica, 4(1), 89-110.

Dreyfus, A.; Husain, O. \& Rouselle-Gay-Crosier, I. (1989). Schizophrénie simple et schizophrénie paranoïde à travers le Rorschach: Étude comparative. Psychologie Medicale, 21(7), 831841.

Guelli, A.V.; Jacquemin, A. \& Santos, M.A. (1996). Análise dos conteúdos de Rorschach de pacientes com distúrbio afetivo bipolar. Medicina Ribeirão Preto, 29(2), 269-277.

Marin, S. (1991-92). Le Rorschach: Evolution de l'image du corps et des kinesthesies. Bulletin de Psychologie, 45(406), 587-593.

Mayman, M. (1967). Object representations and object relationships in Rorschach responses. Journal of Projective Techniques \& Personality Assessment, 31, 17-24.

Meissner, W.W. (1979). Internalization and object relations. Journal of the American Psychoanalytic Association, 27(2), 345-360.

Modell, A.H. (1963). Primitive object relations and the predisposition to schizophrenia. International Journal of Psycho-analysis, 44, 282-292.

Modell, A.H. (1973). Amor objetal e realidade: Uma introdução à teoria psicanalítica das relações amorosas. (M. B. Machado, Trad.) Rio de Janeiro: Imago.

ORGANIZAÇÃO MUNDIAL DE SAÚDE (1978). Os transtornos mentais: Classificação Internacional de Doenças, $9^{a}$ revisão. Vol. I. Cap. V,

Perse, J. \& Massuyeau, Y. (1984). Exist-t-il des signes

Paidéia, FFCLRP-USP, Rib. Preto, ago/dez/2000. pathognomoniques de schizophrénie dans le test de Rorschach? Revue de Psychologie Appliquée, 34(1), 59-74.

Rausch de Traubenberg, N. (1975). A prática do Rorschach. (A. Cabral, Trad.) São Paulo: Cultrix.

Rausch de Traubenberg, N. (1981). Représentation de soi, identité et identificacion chez l'enfant et chez l'adult au Rorschach International Congress of Rorschach and Projective Techniques: Book of abstracts, Washington: SIRMP.

Rausch de Traubenberg, N. (1983). Activité perceptive et activité fantasmatique au test de Rorschach. Le Rorschach: espace d'interactions. Psychologie Française, 28(2), 100-103.

Rausch de Traubenberg, N. (1986). Le Rorschach, espace d'interactions. Bulletin de Psychologie, 39(376), 659-661.

Rausch de Traubenberg, N. \& Boizou, M.F. (1977). Le Rorschach en clinique infantile, l'imaginaire et le réel chez l'enfant. Paris: Dunod.

Rausch de Traubenberg, N.; Bloch-Laine, F; Boizou, M.-F.; Duplant, N.; Martin, M. \& Poggionovo, M.-P. (1990). Modalités d'analyse de la dynamique affective au Rorschach: Grille d'analyse de la dynamique affective. Revue de Psychologie Appliquée, 40(2), 245-258.

Sanglade, A. (1983). Image du corps et image de soi au Rorschach. Techniques Projectives II. Psychologie Française, 28, 104-110.

Santos, M.A. (1991). Imagem do corpo e investimento da estrutura corporal peculiares à esquizofrenia. Comunicações Científicas, Programa e Resumos da XXI Reunião Anual de Psicologia_(p. 218), Ribeirão Preto: SPRP.

Santos, M.A. (1992). O teste de Rorschach na investigação da personalidade na esquizofrenia. Dissertação de Mestrado, Universidade de São Paulo, São Paulo.

Santos, M.A. (1996a). A representação de si e do outro na esquizofrenia: um estudo através do exame de Rorschach. Tese de Doutorado, Universidade de São Paulo, São Paulo.

Santos, M.A. (1996b). Aplicações da prova de Rorschach no campo da psicopatologia. Em 
Jacquemin, A.; Okino, E. T. K. \& Vendrúsculo, J. (Eds.) Anais do I Encontro da Sociedade Brasileira de Rorschach e Outros Métodos Projetivos (pp. 257-281). Ribeirão Preto: SBRo.

Santos, M.A. (1997). O estatuto da representação de si na esquizofrenia. Em Jacquemin, A. \& Okino, E. T. K. (Eds.) Anais do II Encontro da Sociedade Brasileira de Rorschach e Outros Métodos Projetivos (pp. 102-114). Ribeirão Preto: SBRo.

Santos, M.A. (1999) A constituição do mundo psíquico na concepção winnicottiana: Uma contribuição à clínica das psicoses. Psicologia: Reflexão e Crítica, 12(3), 603-625.

Santos, M.A. \& Jacquemin, A. (1990a). Le Rorschach dans la schizophrénie: Etude des contenus avec la Grille de Représentation de Soi. XIIIème Congrès Internationale du Rorschach et des Méthodes Projectives - Volume des resumes (s/p, resume 234), Paris: Centre de Psychologie Appliquée - SIRMP.

Santos, M.A. \& Jacquemin, A. (1990b). Representação de objeto através do teste de Rorschach: Análise da distribuição de respostas relativas às diferentes categorias de conteúdo humano em uma amostra de esquizofrênicos. Programa $e$ Resumos da XX Reunião Anual de Psicologia (p. 155), Ribeirão Preto: SPRP.

Schafer, R. (1960). Bodies in schizophrenic Rorschach responses. Journal of Projective Techniques, 24(3), 267-281.

Silverman, L.H. (1970). On the relationship between aggressive activation, symbiotic merging, intactness of body boundaries, and manifest pathology in schizophrenics. Journal of Nervous and Mental Disease, 150(5), 387-399.

Silverman, L. H. \& Candell, P. (1963). On the relationship between aggressive imagery and thought disturbance in Rorschach responses. Journal of Projective Techniques and Personality Assessment, 27(3), 336-342.

Timsit, M. \& Gross, W. (1989). Identité et relation chez des patients schizophrènes et leur mère à travers le Rorschach de couple. Psychologie Medicale, 21(7), 809-824.
Winnicott, D.W. (1978). Psicose e cuidados maternos. Em D.W. Winnicott (Org.), Textos selecionados: da pediatria à psicanálise (pp. 375-387). (J. Russo, Trad.), 2." ed. Rio de Janeiro: Francisco Alves.

\section{Apoio CAPES \\ Bolsa Doutorado}




\section{Anexo 1 \\ CRITÉRIOS PARA A AVALIAÇÃO DA REPRESENTAÇÃO DE SI, SEGUNDO ARCOSTANZO \& COLS. (1989), TRADUZIDOS POR SANTOS (1996a)}

A avaliação se baseia na qualidade da representação de si, no sentido positivo (+), negativo (-) ou intermediário (+/-), com base em critérios específicos e diferenciados para as pranchas de I a VII, e para as pranchas em tom pastel (VIII a X).

\section{Critérios para as pranchas de I a VII:}

\section{A. Conotação positiva (+):}

1) Nas pranchas compactas (I, IV, V e VI), as interpretações são unitárias, com correta percepção da relação figura/fundo e boa qualidade formal, índice de uma boa capacidade de individuação: Pr. I: "uma borboleta"; Pr. IV: "um monstro humano" (na Itália, um "orco", que é uma espécie de besta imaginária, usada para assustar as crianças); Pr. V: "um morcego"; Pr. VI: "pele de animal" (na Itália, um "gato").

Satisfeito esse critério, a prancha I também é avaliada positivamente ainda nos seguintes casos: - interpretação global combinatória tripartite, somente quando tal percepção implica um determinante cinestésico indicativo do acesso à individuação, isto é, uma resposta representativa de uma individuação já alcançada pelo sujeito (Por exemplo: Pr. I: "dois marinheiros que têm uma bússola");

- interpretação do D central com conteúdo $\mathrm{H}$, valorizando-se em tal percepto o investimento identificatório já adiantado, evoluído, que frequientemente pode vir a conotar sexualmente a imagem de si (Pr. I: "uma mulher com a mão erguida").

Já a prancha IV só é avaliada positivamente quando a interpretação remete à figura humana, ou a qualquer outra coisa que a simbolize, como pessoa, corpo, chimpanzé, árvore, considerando-se o elevado nível evocativo da prancha.

Diante da resposta fornecida à prancha IV, em que o $\mathrm{D}$ central inferior não vem integrado no percepto, avaliar positivamente, retendo, contudo, tal evitamento em uma abordagem ulterior, já que ele é indicativo de problemática no registro genital, inerente à dificuldade de integração da identidade.

A prancha $V$ é avaliada positivamente quando aparece a interpretação de animal alado (morcego, borboleta, libélula, inseto com asas). A ausência de reconhecimento de um conteúdo evocado com muita freqüêencia é indicativa de grave incapacidade de representação de si e do próprio mundo objetal.

2) Nas pranchas II, III e VII a percepção da bilateralidade com boa qualidade formal evoca a possibilidade de desenrolar-se o processo de individuação-separação; o conteúdo pode ser $\mathrm{H},(\mathrm{H})$, A, para as pranchas II e VII, mas para a prancha III se exige exclusivamente a interpretação da figura humana.

B. Conotação negativa (-):

1) Nas pranchas compactas comparece o duplo: o eixo central é percebido como linha de cisão, mais do que como linha organizadora/integradora ( $\mathrm{Pr}$. $\mathrm{V}$ : "dois crocodilos que se afastam, se distanciam um do outro").

2) Nas pranchas II, III e VII não aparece a resposta bilateral, mas a resposta global, com má qualidade formal, ou o dado perceptivo vem fragmentado por causa da angústia, colocando em questão a identidade (Pr. II: "uma borboleta furada"; Pr. III: "uma mulher gorda com a perna torta").

3) Interpretação do branco, seja como fusão ou como inversão figura/fundo, o que indica a dificuldade de diferenciação do contexto, ou mesmo uma falha na representação de si. $\mathrm{O}$ mesmo se pode dizer da distorção perceptiva, frequiente em prancha bilateral, como evidenciado nos exemplos precedentes.

4) Presença de choque, como sinal de destruição da imagem de si diante de forte estimulação emotiva. Para o presente estudo, consideramos ainda a presença de outros fenômenos especiais, tais como recusa ou denegação de resposta fornecida inicialmente.

5) Presença de contaminação e/ou conteúdo Anat, raio-X, Hd, Ad, entendidos como projeção distorcida e angustiante da imagem de si.

C. Conotação intermediária $(+/-$ ou $-/+)$ : Atribui-se a valorização $+/$ - quando o con- 
teúdo oscila de um pólo positivo para um pólo negativo, ou a valorização $-/+$, quando ocorre o inverso. Por exemplo: Pr. V: "esta me lembra uma borboleta... também dois crocodilos".

\section{Critérios para as pranchas pastéis (de VII a X):}

A particularidade dessas pranchas consiste em evocar a emotividade, a afetividade e, segundo Arcostanzo e cols. (1989), a possível integração desse componente ao Eu. A influência da cor, juntamente com a complexidade particular do dado perceptivo, faz com que seja necessária a formulação de critérios específicos para essas pranchas.

\section{Prancha VIII:}

A interpretação da representação de si nessa prancha leva em consideração a presença de uma estrutura tripartite no centro, organizada ao longo de um eixo central que remete à auto-representação (por exemplo, "árvore") e, lateralmente, a presença de dois animais que, por seu caráter banal, remete à relação com a realidade externa. Todos esses elementos formam uma estrutura referente à relação do $\mathrm{Eu}$ com o mundo. Em seu registro mais evoluído, mostra a possibilidade de o sujeito identificar-se com um aspecto da realidade ("animal") sem perder de vista a própria identidade (estrutura geral).

\section{A. Conotação positiva (+):}

1) Resposta que individualiza, na estrutura central, uma representação de si, mas que não evoca explicitamente a relação ("marciano", "árvore", "animal");

2) Resposta em que aparece, claramente percebida, seja a estrutura central, seja a banalidade lateral, como perceptos distintos entre si, independentemente da relação ("esquilos que trepam em uma árvore"; "dois lobos que estão dilacerando um papagaio"; "hiena que está consumindo a carcaça de um animal morto").

\section{B. Conotação negativa (-):}

1) A prancha é percebida de um modo fragmentado ("flores", "manchas coloridas");

2) Só é interpretada a resposta Ban, enquanto índice de provável adesão estereotipada ao real, com incapacidade de representar-se autenticamente ("dois animais... no centro não saberia dizer");

3) A relação é anulada na globalização do percepto ("um mapa-mundi", "uma panela").

\section{Prancha IX:}

Não obstante a dificuldade estrutural específica dessa prancha, evidenciada na ausência de resposta banal e da alta porcentagem de recusa, Arcostanzo e cols. (1989) julgam que a representação de si é comum e possível.

\section{A. Conotação positiva (+):}

1) Resposta global e bem estruturada em torno de um eixo central, com suficiente integração entre forma e cor ("toureiro com a mão sobre a cintu$r a$ ", "sorvete de morango, menta e laranja");

2) Um ou mais detalhes, na sua totalidade, são interpretados como $\mathrm{H},(\mathrm{H}), \mathrm{A}$, com boa qualidade formal (<: "homem sobre sua vespa", no D central);

3) O D superior é percebido bilateralmente e, a um nível mais evoluído, também em relação ("dois gnomos que combatem").

\section{B. Conotação negativa (-):}

1) Qualquer interpretação do detalhe intramacular, compreendendo inclusive conteúdos $\mathrm{H}$ e Hd, indicando uma representação de si no vazio ("testa de cervo entre as moitas", "âmbula de vidro", "uma mulher de costas").

\section{Prancha X:}

$\mathrm{Na}$ falta de um eixo central que estruture o todo na prancha $X, o D$ superior cinza em cima do $D$ rosa simétrico permite uma delimitação entre um dentro e um fora, o que proporciona a diferenciação do Eu em relação ao mundo externo, como reação a um estímulo fragmentado.

\section{A. Conotação positiva (+):}

1) $O$ dado perceptivo é estruturado de um modo coerente, mediante a resposta globalizante (integração do espaço em branco), com boa qualidade formal e com componente de perspectiva ("bosque circundado de animais e no meio um castelo"; "vista de Paris com a Torre Eiffel e o Champs Elysées");

2) O D central é organizado em uma única 
representação com conteúdo $\mathrm{H}$, $(\mathrm{H})$ ou Hd ("homem com capa"; "face, testa de monstro");

3) Os D rosa, verde ou azul central são interpretados como $\mathrm{H}$ ou $(\mathrm{H})$; nesse caso, o sujeito, mediante o isolamento, se defende da fragmentação de um modo evoluído.

B. Conotação negativa (-):

1) A resposta, quando globalizante, soa incongruente ("Torre Eiffel que se eleva com quatro pilares sobre Puglia às avessas");

2) Percepção apenas do D lateral Ban ("caranguejo"), indicativa, como na prancha VIII, de uma provável adequação estereotipada à realidade, em detrimento da autenticidade do Eu;

3) Resposta que compreende toda a prancha, sendo que os limites da representação são os mesmos do estímulo, um processo indicativo de ausência ou perda da fronteira entre o interno e o externo ("quadro abstrato"; "zoológico"; "aquário").

Para Arcostanzo e cols. (1989), as pranchas pastéis têm sempre uma conotação negativa quando contêm respostas Anat ou estão associadas a fenômenos especiais, tais como: contaminação, choque e recusa.

\section{Conotação intermediária (+/- ou $-/+)$ :}

Para a cotação da conotação intermediária das representações de si contidas nas interpretações dadas nas pranchas pastéis, vale o critério adotado para as primeiras pranchas, ou seja, a oscilação das conotações de um pólo negativo para um pólo positivo (ou vice-versa). 